\title{
A CULTURA DIGITAL, A SEMIFORMAÇÃO E O NOVO ELO PEDAGÓGICO*
}

\author{
ANTÔNIO A. S. ZUIN \\ Universidade Federal de São Carlos, São Carlos, São Paulo, Brasil
}

\begin{abstract}
Resumo: Hoje, os indivíduos viciam-se por estímulos audiovisuais, propagados pelas telas onipresentes em todas as relações sociais. Desde elevadores até bares e restaurantes lotados em que se transmitem as notícias mais atuais, nota-se a presença da tela que se universaliza nas relações de trabalho e de tempo livre, as quais, não por acaso, aproximam-se cada vez mais. Diante desse contexto histórico, torna-se imprescindível analisar o modo como as novas formas de produção e disseminação das informações redirecionam os vetores da relação professor-aluno. Seguindo essa linha de raciocínio, o principal objetivo deste artigo é analisar tais transformações da relação professor-aluno em tempos da chamada cultura digital.
\end{abstract}

Palavras-chave: Cultura digital. Semiformação. Indústria cultural. Elo pedagógico.

\section{INTRODUÇÃO}

A atual forma de produção e disseminação das informações pode ser classificada como revolucionária, em decorrência de como as forças produtivas contemporâneas se desenvolvem em meio à consolidação do chamado capitalismo transnacional. A cada dia, surgem novidades tecnológicas que parecem dirimir a distância dos seres humanos em relação aos deuses outrora idolatrados, a ponto de a expressão deus ex machina ser, literalmente, revitalizada na atual sociedade ultratecnológica. Com efeito, se tal expressão, na Grécia antiga, caracterizava os atores que representavam deuses nas peças teatrais encenadas naquele período, nos dias de hoje, a

\footnotetext{
* Artigo recebido em 31/5/2013 e aprovado em 15/8/2013.
} 
fusão entre ser humano e máquina chega ao ponto de produzir indivíduos biônicos, cujas próteses de carbono e circuitos sofisticadíssimos podem ser controladas por meio de impulsos elétricos emitidos por chips conectados aos cérebros.

Se a atual conexão homem-máquina confirma previsões dos romances de ficção científica do século $X X$, não menos impressionante é a condição de acesso a informações, possibilitada pela Internet aliada aos meios de comunicação de massa. Aliás, a expressão comunicação de massas é esclarecedora por si própria, uma vez que pessoas das mais variadas regiões do planeta podem conectar-se em tempo real e a qualquer momento. São tempos nos quais um bilhão de pessoas se comunica por meio do Facebook, em um planeta de cerca de sete bilhões de habitantes. Hoje, a produção e disseminação das informações atingem patamares imaginados apenas nos romances citados. A acessibilidade a informações, por meio do uso da Internet, torna-se possível muito em função da portabilidade dos smartphones, os i-pads, tablets etc.

Por certo, a convergência entre acessibilidade e portabilidade expressa o modo como uma nova cultura - denominada pelos pesquisadores como digital - se consolida. Mas a cultura digital não pode ser caracterizada exclusivamente por meio do modo como novas técnicas de comunicação revolucionam a fabricação e profusão de aparelhos capazes de provocar inveja no deus Hermes (ou Mercúrio), que tinha asas nos pés, que lhe possibilitavam transpor grandes distâncias em um breve intervalo de tempo. $\mathrm{Na}$ verdade, a produção de um novo paradigma comunicacional precisa ser compreendida na sociedade em que todas as relações sociais tendem a ser concretizadas através de telas e displays. A constatação de que os atuais indivíduos são tecnologizados implica na investigação do que significa ser digitalmente tecnologizado.

Nessa conjuntura, as escolas e seus respectivos agentes educacionais procuram adaptar-se a essa nova realidade, cujas relações objetivas tornamse, cada vez mais, virtuais; para que uma escola esteja up to date, ou seja, possa ser identificada como atualizada, tais agentes alardeiam a compra de lousas digitais, aparelhos de televisão com recursos de terceira dimensão e computadores de última geração. Contudo, para além do contato com tais aparatos, torna-se imprescindível analisar a maneira como as novas formas de produção e disseminação das informações redirecionam, de modo inédito na história do desenvolvimento do trato pedagógico, os vetores da relação professor-aluno. Seguindo essa linha de raciocínio, o principal objetivo deste artigo é analisar tais transformações da relação professor-aluno em 
tempos da chamada cultura digital, o que implica, em um primeiro momento, refletir sobre como a indústria cultural fomenta a produção da denominada semiformação.

\section{A INDÚSTRIA CULTURAL E A SEMIFORMAÇÃO COMO FRAQUEZA DA MEMÓRIA}

De acordo com Theodor W. Adorno (1994, p. 92), tudo indica que o conceito indústria cultural foi apresentado pela primeira vez no livro Dialética do esclarecimento: fragmentos filosóficos. Escrito em parceria com Max Horkheimer, e considerado por muitos teóricos como uma das principais obras do século $X X$, destaca-se o Capítulo "A indústria cultural: o esclarecimento como mistificação das massas". De fato, a expressão "mistificação das massas" (Massenbetrug) pode muito bem ser lida como engodo das massas. Ou seja, a definição do conceito de indústria cultural remeteria ao processo social que determinou o fato de o esclarecimento (Aufklärung) ter se transformado em uma ilusão das massas; os indivíduos que as compuseram, kantianamente falando, deveriam ter se emancipado de sua condição de menoridade, na medida que se apropriassem da promessa de felicidade contida nos chamados produtos culturais massificados e, de forma gradativa, a concretizassem.

O conhecido texto de Kant - Resposta à pergunta:que é esclarecimento - coaduna a condição de indivíduo letrado à possibilidade do exercício público da razão, o que facultaria a esse mesmo indivíduo a capacidade de criticar as regras às quais se submetesse na esfera privada, desde que participasse de alguma instituição específica, tais como a Igreja, a Escola ou o Exército. Escrito no final do século XVIII, esse texto consagrou a expressão latina sapere aude; o ousar saber como prerrogativa do indivíduo que não mais se conforma com seu estado de tutelado e ousa fazer uso de seu próprio entendimento, sem que seja controlado pelos mandos e desmandos de outros indivíduos (KANT, 2005). Mas, para que pudesse ousar saber e afirmar sua condição de maioridade, seria fundamental que o sujeito dominasse as premissas do mundo letrado. Não por acaso, os sistemas nacionais de ensino consolidaramse em vários países europeus no século XIX. Também, não foi fortuito o fato de que as estruturas objetivas do conceito de formação cultural (Bildung) espraiaram-se simultaneamente com a afirmação político-econômica do modo de produção capitalista. A esperança de uma sociedade mais justa e democrática, que teria como fundamento principal a efetivação do processo formativo, foi descrita por Adorno da seguinte forma:

A formação devia ser aquela que dissesse respeito - de uma maneira pura como seu próprio espírito - ao indivíduo livre e radicado em sua própria cons- 
ciência, ainda que não tivesse deixado de atuar na sociedade e sublimasse seus impulsos. A formação era tida como condição implícita a uma sociedade autônoma: quanto mais lúcido o singular, mais lúcido o todo. Contraditoriamente, no entanto, sua relação com uma práxis ulterior apresentou-se como uma degradação a algo heterônomo, como percepção de vantagens de uma irresolvida bellum omnium contra omnes. (ADORNO, 2010, p. 13)

É interessante observar o modo como Adorno denota a danificação da formação cultural na sociedade na qual os indivíduos estabelecem a guerra de todos contra todos, mesmo que, de forma ideológica, prevaleça a assertiva de que todos teriam as mesmas chances de ascensão social, de acordo com as promessas contidas nos contratos sociais do modo capitalista de produção e reprodução da existência humana. No que concerne à esfera subjetiva, não menos interessante é a relação estabelecida por Adorno entre formação cultural, autonomia e sublimação de impulsos. O exercício de autonomia do indivíduo livre e radicado em sua própria consciência não seria apartado da necessidade de sublimação dos impulsos, sendo essa a condição central para a consolidação do processo cultural e/ou civilizatório. Essa relação entre formação, autonomia e controle pulsional também foi expressa, ainda que em outro contexto, por Rousseau, o filós ofo genebrino tão admirado por Kant. No transcorrer do processo formativo de Emílio, seu aluno imaginário, Rousseau enfatizou a importância de que seu discípulo soubesse controlar, por meio da razão, a relação entre a realização de seus desejos e as regras dos contratos sociais, cujas premissas também seriam definidas pelo educando junto a seu mestre. Na medida que Emílio se tornasse capaz de, verdadeiramente, ouvir as vozes de suas disposições naturais, haveria uma chance de ocorrer um equilíbrio entre a concretização de seus desejos e a obediência às regras dos contratos sociais (ROUSSEAU, 1992).

Porém, foi o mesmo Rousseau, o iluminista herético - para fazer uso da caracterização feita por Reale e Antiseri (1990, p. 775) -, que denunciou a hegemonia de uma educação hipócrita na França do século XVIII. Ou seja, uma educação aparentemente balizada no exercício da razão, mas que, na realidade, produzia indivíduos preocupados exclusivamente com a realização de seus próprios desejos. Baseado nessa observação crítica de Rousseau, Kant definiu tal aparência de moralidade da seguinte forma:

Mediante a arte e a ciência, nós somos cultivados em alto grau. Nós somos civilizados até a saturação por toda espécie de boas maneiras e decoro sociais. Mas ainda falta muito para nos considerarmos moralizados. Se, com efeito, a ideia de moralidade pertence à cultura, o uso, no entanto, dessa ideia, que 
não vai além de uma aparência de moralidade (Sittenähnliche) no amor à honra e no decoro exterior, constitui apenas a civilização. (KANT, 1986, p. 19)

A cisão destacada por Kant entre civilização e cultura, sobretudo quanto à supremacia da aparência de moralidade, precisa ser compreendida em decorrência do modo como a indústria cultural consolida-se, de forma gradativa, tanto na produção e disseminação em massa dos chamados bens culturais, quanto nos prejuízos decorrentes da esfera subjetiva, identificados por Adorno através do conceito de semiformação. De acordo com o pensador frankfurtiano, a semiformação caracteriza-se como a conquista do espírito pela lógica do fetiche da mercadoria cultural, a tal ponto que, na sociedade da semiformação hegemônica, "Nada detém o espírito, então, para um contato corporal com as ideias" (ADORNO, 2010, p. 21). Ou seja, ao invés de ocorrer o aprofundamento do raciocínio - de modo que a informação obtida seja criticamente refletida a ponto de transformar-se em conceito -, tem-se um estado de supremacia de informações efêmeras e incrivelmente pontuais.

É nesse contexto que o indivíduo semiformado justifica a superficialidade de seus raciocínios, pois não possui o tempo necessário para aprofundálos. Em termos filosófico-educacionais, compreende-se então essa ausência de comunicação corporal entre o espírito (ou seja, a própria subjetividade) e as ideias. A velocidade de composição e reposição das mercadorias ditas culturais não é compatível com o tempo de maturação do raciocínio crítico. É nesse sentido que o mediato passa a ser substituído pelo imediato. Em outros termos: as relações históricas que compõem a tessitura das mercadorias culturais tornam-se obnubiladas diante do sortilégio dos estímulos audiovisuais dessas mesmas mercadorias. A maneira como a semiformação solapa a memória foi assim caracterizada por Adorno:

A experiência - a continuidade da consciência em que perdura o ainda não existente e em que o exercício e a associação fundamentam uma tradição no indivíduo - fica substituída por um estado informativo pontual, desconectado, intercambiável e efêmero, e que se sabe que ficará borrado no próximo instante por outras informações [...]. A semiformação é uma fraqueza em relação ao tempo, à memória, única mediação capaz de fazer na consciência aquela síntese da experiência que caracterizou a formação cultural em outros tempos. (ADORNO, 2010, p. 33)

Justamente por ser uma fraqueza em relação ao tempo e à memória, a semiformação impede que novas alternativas de identidade sejam engendradas, de tal modo que o ainda não existente, bem pouco provável, poderá ser efetivado. A produção e reprodução das mercadorias da indústria 
cultural nutrem-se, de forma específica, desse solapamento da experiência formativa, que teria como alicerce o contato corporal do espírito com suas mediações históricas, em virtude da disseminação, cada vez maior, de um estado informativo pontual, desconectado, intercambiável e efêmero.

Adorno relacionou a semiformação com a erosão da memória no final da década de 1950. Já em tempos da chamada cultura digital, produto da revolução microeletrônica consolidada na década de 1980 no denominado vale do Silício nos EUA, de que modo o conceito de semiformação poderia ser revitalizado? E mais: em tempos nos quais tudo pode ser lembrado (SCHÖNBERGER, 2009), uma vez que quaisquer informações são acessadas por meio do clicar de um mouse, poder-se-ia afirmar que a semiformação não mais existiria? Pois se a semiformação pode ser identificada como a destruição da memória, o que dizer de uma sociedade cujas forças produtivas, de ordem tecnológica, permitem fazer com que absolutamente tudo possa ser lembrado?

São questões como essas que fomentam a reflexão sobre o modo como a indústria cultural contemporânea promove a produção e disseminação de informações, fato esse que está determinando modificações profundas também nas relações estabelecidas entre professores e alunos.

\section{A CULTURA DIGITAL, A DISTRAÇÃO CONCENTRADA E O PANÓPTICO ATEMPORAL}

Em agosto de 2012, uma aluna do ensino fundamental, de uma escola da rede pública de Florianópolis, capturou a atenção da mídia nacional e internacional por meio da publicação de um diário de classe virtual em sua página do Facebook. Intitulado "Diário de classe: a verdade...", a aluna postou comentários e imagens sobre portas e fechaduras danificadas de sua escola. Em decorrência da repercussão midiática que tal diário conquistou, os gestores educacionais providenciaram o conserto imediato de tais portas. A mesma aluna postou também um vídeo criticando o professor de matemática que, de acordo com o depoimento dela, não era capaz de disciplinar sua turma, fato esse que comprometeria a qualidade das aulas ministradas. Dessa vez, tanto a Escola quanto a Secretaria de Educação de Florianópolis rapidamente agiram, já que o professor foi demitido em caráter temporário.

Tais atitudes da Escola e da Secretaria de Educação são expressões do atual espírito do tempo; as imagens como que adquirem uma conotação metafísica universal: elas como que bastam em si e por si. Seu caráter imediato Ihes provê a condição de verdade irredutível, de modo especial, quando determinadas imagens conseguem vencer a luta titânica que travam com outras, a ponto de sua exposição global capturar a atenção do maior número 
possível de consumidores de estímulos audiovisuais. Os mais de 400.000 seguidores da aluna em sua página do Facebook, além da exposição do caso através de vários canais de televisão, blogs e portais da Internet facultaramIhe o poder de julgar o professor e estabelecer a sentença em escala global: trata-se de um péssimo docente. Não houve sequer a preocupação de que se investigassem as origens dos possíveis problemas enfrentados por ele. Ao invés de fomentarem relações dialógicas com o professor, também os gestores educacionais logo o sentenciaram, sobretudo em função do receio de que uma possível imagem de descaso lhes fosse associada e, então, transmitida pelos mais variados meios de comunicação de massa. $E$ mesmo que tal professor consiga obter na justiça o direito de que esse vídeo seja apagado do Facebook da aluna, uma vez que não teve sequer como defender-se de todas as acusações que lhe foram imputadas, a sua imagem de docente relapso permanecerá nas redes sociais, pois poderá ser acessada a qualquer momento e em qualquer circunstância. Desse modo, a imagem e os comentários postados não mais são considerados como possíveis de representar a realidade, mas, sim, transformam-se na própria.

Há outro caso que precisa ser lembrado: trata-se da aluna de pedagogia de uma faculdade de educação dos EUA que, em 2006, postou uma foto sua no MySpace, vestida de pirata e com uma caneca de bebida na mão. A foto recebeu o título de "pirata bêbada", e foi tirada em uma festa de comemoração de final de curso. A direção da faculdade teve acesso à foto e expulsou a aluna do curso poucos dias antes de formar-se pedagoga, alegando que essa não era uma imagem compatível com a de uma profissional da área de educação, formada por aquela instituição (SCHÖNBERGER, 2009, p. 1-4).

Seguindo essa linha de raciocínio, a atual cultura digital revitaliza o conceito do panóptico - tal como foi cunhado por Bentham e amplamente divulgado por Foucault no seu livro Vigiar e punir: nascimento da prisão (FOUCAULT, 2001) -, pois as informações e imagens postadas na Internet podem ser recuperadas a qualquer momento e em quaisquer situações, ao mesmo tempo que são majoritariamente utilizadas para julgar, controlar e punir. É evidente que a recuperação de imagens e informações possibilita melhorias nas mais variadas áreas de conhecimento, de modo particular, em função da possibilidade de se estabelecer intercâmbios informativos em uma velocidade que permite essas trocas em tempo real. A convergência atual proporcionada pelas novas mídias - desde que a acessibilidade e a portabilidade de aparelhos permitem fazer com que novas formas de interação entre as pessoas se desenvolvam - envolve, também, permuta de conhecimentos que aproximam, cada vez mais, áreas como informática, biologia e medicina, por exemplo. A título de exemplo, hoje, há uma corrente na pedagogia que defende a ideia 
de que os princípios da nanociência possam funcionar como catalisadores de uma reforma educacional, de tal maneira que a discussão ética da presença da nanotecnologia torne-se ainda mais atuante nas instituições escolares (SCHANK; KRAJCIK; YUNKER, 2007).

Contudo, o acesso a informações e imagens não pode ser apartado das relações humanas que as engendraram, pois, em muitas ocasiões, ocorre o reforço do preconceito, do pensamento estereotipado e da atualização da mentalidade do ticket, tal como foi definida por Adorno nos seus estudos sobre a personalidade que, de forma autoritária, rotula o outro ao atribuir-lhe determinadas etiquetas preconceituosas e fascistas (ADORNO, 1972). Assim, as pessoas, associadas às imagens que as representam, são julgadas a despeito das mediações histórias que determinaram as cores e tonalidades das próprias imagens. Daí a presença, cada vez mais constante, do panóptico atemporal.

É importante observar que a presença de tal panóptico consubstanciase com a forma como a indústria cultural contemporânea se desenvolve, sobretudo em tempos da chamada cultura digital. Pois é nesses tempos da digitalização das relações culturais que se consolida e se espraia o que Christoph Türcke denominou como distração concentrada.

Ao acessarmos determinada informação através dos mais variados sites, a capacidade de atenção é estilhaçada assim que novos links, ou seja, novas ligações com outros sites têm êxito em conquistar nosso interesse, ainda que por um momento, de tal forma que "o meio de concentração se torna o próprio meio de decomposição" (TÜRCKE, 2010, p. 266). O fenômeno da distração concentrada não pode ser atribuído, com exclusividade, ao comportamento de indivíduos portadores dos chamados déficits de atenção, pois a dificuldade de concentração necessita ser entendida como um produto do modo como o conhecimento é produzido e reproduzido na era da chamada cultura digital. É nessa sociedade específica que a tela, "o grande recheio do tempo livre, penetrou profundamente, por meio do computador, o mundo do trabalho; a coordenação de processos inteiros de produção e administração perpassa por ela, de tal modo que se apresenta como o ensino do futuro" (TÜRCKE, 2010, p. 266-267).

É sintomática a forma como, nos dias atuais, os indivíduos viciam-se por meio do consumo de estímulos audiovisuais, propagados pelas telas que se tornam onipresentes em todas as relações sociais. Desde elevadores que possuem telas transmitindo as notícias mais atuais, até bares e restaurantes lotados de aparelhos de televisão que transmitem, ao mesmo tempo, quatro ou cinco diferentes programas, a tela universaliza-se nas esferas do trabalho e do tempo livre, as quais, não por acaso, aproximam-se cada vez 
mais. Não que tal aproximação seja uma característica exclusiva da cultura digital, pois há várias profissões, como a dos professores, cujos limites entre o tempo livre o trabalho sempre foram tênues. Mas é no contexto atual que essas fronteiras tendem a ser destruídas, justo porque as atuais relações de produção impingem tal necessidade, exatamente no momento histórico no qual o desenvolvimento das forças produtivas, sobretudo as de ordem tecnológica, realiza a fratura de tais limites. As respostas dos e-mails precisam ser elaboradas de imediato, caso contrário corre-se o risco de ser identificado como deselegante, por conta da "demora" da resposta, ou mesmo de se perder uma excelente oportunidade profissional, caso a caixa de e-mails não seja conferida várias vezes ao dia.

O vício de consumo de estímulos audiovisuais não pode ser atribuído apenas aos adultos que passam horas do dia e da noite jogando videogames on line; também nas crianças podem ser notados sinais de síndrome de abstinência, caso sejam impedidas de consumir esses estímulos por meio do uso da televisão ou dos computadores. Não há consenso sobre os efeitos psicocognitivos e afetivos relacionados ao consumo praticamente ininterrupto de tais estímulos. Há quem afirme que novas habilidades passam a ser desenvolvidas, como a capacidade de fazer várias atividades ao mesmo tempo, ou mesmo a rapidez de reposta que é exigida cada vez que se joga um videogame, por exemplo. Contudo, não há como negar que se torna cada vez mais problemática a capacidade de o indivíduo relacionar, por meio de um eu estruturado e consistente, a torrente de informações com a qual se depara no seu cotidiano. Günther Anders já havia observado a presença dessa dificuldade em meados do século XX, quando apresentou o caso de um homem tomando banho de sol, ou seja, do indivíduo

que bronzeia suas costas, enquanto que seus olhos deslizam por uma revista ilustrada, seus ouvidos participam de jogo esportivo, seus dentes mascam uma goma [...]. Se fosse perguntado a esse homem tomando banho de sol no que consistiria sua atividade "real", é claro que ele não poderia responder, pois a pergunta por algo de "real" já se baseia em uma falsa pressuposição; a saber, que ele seria o sujeito das atividades e do deter-se em algo. Se aqui ainda se pode falar de "sujeito" ou "sujeitos", os termos têm que se referir aos seus órgãos: aos olhos que se detêm sobre as fotos; aos ouvidos que se detêm sobre os jogos esportivos; aos dentes que se detêm sobre a goma de mascar [...]. Seu trabalho acostumou-o tão definitivamente a ser ocupado, ou seja, a ser dependente, que, quando o trabalho acaba, não consegue estar à altura da tarefa de ocupar de si próprio. E, assim, [...] decompõe-se em funções separadas, já que ele mesmo não atua como elemento organizador. (ANDERS, 2002, p. 138-139) 
A decomposição do homem que toma banho de sol em funções separadas revela a incomunicabilidade dos sentidos; esses parecem bastar a si próprios, independentes de um eu que seja capaz de relacioná-los. Se houvesse tal comunicabilidade, então, o choque sensorial proveniente da fricção entre os estímulos olfativo, ótico, tátil, auditivo e gustativo incitaria o indivíduo a desenvolver representações complexas, as quais poderiam transformar-se em conceitos. Como isso dificilmente ocorre - ao invés de assenhorear-se dos sentidos para que possa reencontrar-se consigo próprio -, o indivíduo contenta-se com a sensação de pré-prazer, proporcionada pela estimulação isolada de cada um deles. Mas como pensar essa constatação de Anders na era da cultura digital? Dito de outra forma: como refletir sobre a incomunicabilidade dos sentidos e, portanto, do fracasso de um eu como elemento organizador, na sociedade da comunicabilidade total?

Quando se compara as estimulações sensoriais propiciadas pela indústria cultural do período - desse texto de Anders, escrito em meados da década de 1950 - com a fase da indústria cultural da era digital, parece que atualmente se confirmam as previsões distópicas, tal como o caso do cinema sensível relatado por Huxley no seu livro Admirável mundo novo. Conectado a aparelhos extremamente sofisticados, o personagem selvagem se extasia diante das cenas de sexo que observa na tela do cinema, ao mesmo tempo que "sente" ser beijado através da ação de tais aparelhos (HUXLEY, 2007, p. 146). Tempos nos quais predominam as telas 3D em cinemas e aparelhos de televisão nas próprias residências não estão tão distantes assim do cinema sensível imaginado por Huxley.

Horkheimer e Adorno já haviam asseverado, na Dialética do esclarecimento, que a indústria cultural não sublima, mas, sim, reprime:

Expondo repetidamente o objeto do desejo, o busto no suéter e o torso nu do herói esportivo, ela (a indústria cultural) apenas excita o prazer preliminar não sublimado que o hábito da renúncia há muito mutilou e reduziu ao masoquismo. Não há nenhuma situação erótica que não junte à alusão e à excitação a indicação precisa de que jamais se deve chegar a esse ponto [...]. A produção em série do objeto sexual produz automaticamente seu recalcamento. (HORKHEIMER; ADORNO, 1986, p. 131)

Na atual sociedade, os chamados produtos "culturais" também são engendrados em série, mas o desenvolvimento tecnológico hodierno possibilita a sensação de fruição do prazer em relação à estimulação sensorial, de tal maneira que quase se pode afirmar que não mais se trata da excitação do prazer preliminar, do pré-prazer, mas, sim, do próprio. Nas telas dos atuais cinemas sensíveis, é quase possível "tocar" as imagens que são projetadas nas 
salas de cinema l-Max. É como se a definição de Horkheimer e Adorno sobre a dessublimação repressiva tivesse que ser reescrita da seguinte maneira: a indústria cultural dessublima e não reprime. Nesse aparente reino de felicidade, uma vez que os desejos parecem poder ser satisfeitos sem que haja quaisquer limites, como ficaria o eu na condição de elemento organizador dos estímulos sensoriais, notadamente os de ordem audiovisual? Diante do atual bombardeamento de tais estímulos, é pouco provável que o indivíduo consiga organizá-los, a ponto de que as relações feitas entre eles produzam representações mentais que, posteriormente, poderiam tornar-se conceitos. Em tempos da hegemonia da distração concentrada, o atual desenvolvimento tecnológico recrudesce a sensação de que há controle total por parte do eu em relação à recepção e fruição dos estímulos.

Na década de 1950, quando Anders ironicamente diagnosticou a fratura de um eu, cujos sentidos como que se individualizavam, um olhar mais atento poderia denunciar a fragmentação do indivíduo, mesmo diante da figura idílica do homem tomando banho de sol. Já na sociedade atual, cada vez mais, essa atenção torna difícil de se fazer presente, sobretudo pelo fato de que o modo de produção das relações determina a consolidação da distração concentrada como a forma de geração e transmissão das informações. É na sociedade vigente que o computador transforma-se em um aparelho que possibilita "a realização de encontros sociais e particulares, processamento e transmissão de dados, a elaboração de atividades de trabalho e de diversão, televisão e comunicação, concentração e dispersão, ser ignorado ou ser percebido, a ponto de todas essas potencialidades se tornarem indiscerníveis entre si" (TÜRCKE, 2010, p. 44).

Na sociedade da audiovisibilidade e da comunicabilidade total, a aparência de moralidade torna-se mais relevante do que a própria moralidade, na medida que a aparência imagética como que universaliza metafisicamente uma nova ontologia: a de que ser significa ser percebido. Assim, se alguém não se emitir por meio eletrônico é como se não existisse fisicamente, em uma espécie de inversão do vetor de importância das formas de comunicação: a comunicação secundária, feita por meio da presença dos aparelhos que mitigam a distância entre os que se comunicam, torna-se mais relevante que a primária, ou seja, a comunicação presencial.

É evidente que as relações estabelecidas entre professores e alunos não podem ser isoladas desse novo contexto social. Tal como já foi destacado, os alunos notaram que o acesso às novas mídias, sobretudo por meio da utilização dos recursos das redes sociais, capacita-os a serem percebidos de uma forma inédita na história das relações pedagógicas (ZUIN, 2012). Embora 
a participação dos alunos nas redes virtuais recrudesça a cada dia que passa, nota-se que os gestores educacionais, em muitas ocasiões, reagem de forma enérgica em relação a tais manifestações. No mês de junho de 2011, uma aluna de uma escola carioca do ensino médio criou um blog para poder ser comunicar com outros alunos a respeito de aulas e dos trabalhos que thes eram atribuídos pelos professores. Quando a direção da escola soube do fato, suspendeu a aluna das aulas, ameaçou processar a mãe da estudante caso a página não fosse imediatamente retirada e manifestou-se da seguinte forma: "A instituição tomou as medidas cabíveis, seguindo sua linha pedagógica, ao constatar que a aluna administrava página na rede social na qual usava o logo da instituição e veiculava material didático do colégio sem autorização e de forma inadequada" (MENCHEN, 2011, p. 11).

Torna-se difícil compreender o significado da linha pedagógica da escola em questão. Ao invés de fomentar o diálogo entre professores, alunos e gestores educacionais sobre a presença e o significado da Internet nas relações estabelecidas no transcorrer do cotidiano escolar, a direção da escola optou pela ameaça e pelo constrangimento da aluna e de sua mãe. Tal atitude releva muito sobre o despreparo dos agentes educacionais em relação aos atuais desdobramentos da cultura digital. Seria necessário haver debate sobre as implicações decorrentes da divulgação de imagens gravadas pelos aparelhos celulares dos alunos e postadas nas redes sociais, da forma de comunicação on line sobre as informações de textos estudados nas respectivas matérias de ensino, da presença cada vez mais constante do chamado cyberbullying cometido entre alunos, e mesmo entre alunos e professores, dentre outros temas. Hoje, parece prevalecer a necessidade de que os alunos aprendam sobre como utilizar instrumentalmente seus computadores nas aulas de informática, a despeito da premência de que esses mesmos alunos sejam incentivados a debater sobre as implicações éticas do uso da Internet, como se o uso instrumental da máquina bastasse em si e por si. Ao procederem dessa forma, os agentes educacionais contribuem, de forma efetiva, para que o pensamento estereotipado e a mentalidade do ticket, os pilares da semiformação, se revitalizem em tempos da supremacia da distração concentrada.

É nesse contexto que a postura do professor, mais do que nunca, torna-se decisiva. Se os alunos pouco se concentram nos conteúdos aprendidos em função das razões expostas, então o professor precisa assumir a condição de elemento organizador não só do próprio eu, como também dos conteúdos que devem ser coletivamente debatidos nas salas de aula. Para tanto, por que não utilizar os recursos da própria Internet para, em uma espécie de atitude de contrafogo, estimular o debate com os alunos? Se em 
uma determinada aula, o professor e/ou os alunos relacionarem o quadro "Guernica", de Picasso, com os horrores da guerra, por que não acessá-lo por meio de um sítio de busca e analisá-lo no momento exato da elaboração das relações, ao invés de ter que se esperar uma semana para que o professor ou os alunos levem, para a aula seguinte, uma cópia em papel do quadro? Esses são exemplos de contrafogos, para se usar uma expressão de Bourdieu (1998), que poderiam ser efetuados na sociedade cujo desenvolvimento das forças produtivas permite fazer com que tudo possa ser lembrado.

\section{CONCLUSÃo}

Se tais exemplos podem se tornar realidades efetivas nas relações estabelecidas entre os professores e os alunos, não se pode evitar a observação crítica de que, nos dias atuais, o panóptico atemporal se fortalece cada vez mais, de tal forma que as relações de poder entre ambos, que anteriormente alicerçavam as bases do currículo oculto, hoje são expostas em escala global. Não por acaso, na atualidade, há forte propensão de determinadas escolas para que câmeras sejam instaladas nas salas de aula, para que os diretores e pais possam ter acesso às imagens dos alunos/filhos em tempo real. Esquecem-se de que, ao procederem dessa forma, instigam os alunos e professores a representarem caricaturas de si mesmos, como se fossem atores de um programa de televisão, ao mesmo tempo que a autoridade do professor é pulverizada por completo.

Já em relação à presença constante da distração concentrada, seria interessante recuperar a questão feita anteriormente: Se a semiformação foi definida por Adorno como a destruição da memória, então ela não mais existiria nos dias atuais? Em verdade, na sociedade na qual se pode lembrar tudo, desenvolvem-se novas formas de esquecimento. Por certo, a série infinita de links - de ligações de uma informação que se justapõe sobre outra - promove a distração concentrada; essa, praticamente, impossibilita que haja tempo necessário para que a informação, ao ser elaborada, transforme-se em representações mentais propícias a se tornarem conceitos.

Mas, se houver esse tempo, a ligação pode, então, ser qualitativamente metamorfoseada em relação, sendo que o termo adquire relevância decisiva quanto à atual forma de produção e reprodução do conhecimento. É irônico notar que, em tempos nos quais a interdisciplinaridade transforma-se em uma necessidade imperiosa em decorrência do atual desenvolvimento tecnológico, a distração concentrada - produzida pelo modo como as relações de produção hodiernas e as forças produtivas interagem - impeça, de forma específica, o aprofundamento do intercâmbio interdisciplinar. Seguindo 
essa linha de raciocínio, as relações entre os conteúdos das mais variadas disciplinas, cada vez mais, precisam ser divulgadas pelo professor. Para tanto, torna-se fundamental que o docente reavalie sua própria condição de educador. Pois, o que significa educar na sociedade da cultura digital, na qual os indivíduos podem acessar quaisquer informações a qualquer momento? Não por acaso, várias vozes se fazem ouvir, inclusive, questionando a existência da escola como instituição produtora e disseminadora do conhecimento, dado que tal acesso a informações solaparia a necessidade de existência da própria instituição escolar.

Porém, é justamente a escola que oferta o ambiente para que se possa refletir sobre o atual rompimento espaço-temporal da cultura, cujas relações humanas, a cada dia, mais se digitalizam. O professor possui papel fundamental no exercício dessa reflexão, na condição de organizador das etapas do processo de ensino e aprendizagem, desde que compreenda que tal organização deva ser feita, também, por meio da participação dos alunos, de tal modo que se arrefeça o poder do panóptico atemporal nas salas de aula, ao mesmo tempo que a palavra diálogo seja ressignificada, de forma qualitativa, no contexto da sociedade da cultura digital.

\section{DIGITAL CULTURE, SEMIFORMATION AND THE NEW PEDAGOGICAL LINK}

ABSTRACT: Nowadays people are addicted to visual stimuli, propagated by omnipresent screens in all social relationships. From elevators to bars and crowded restaurants with television sets transmitting the latest news, the screen is universalized in the relations of work and free time. It is no coincidence that these relations are coming closer together. In this historical context, it is vitally important to analyze how the new forms of production and dissemination of information redirect the vectors of teacher-student relationships. Following this line of reasoning, the main aim of this article is to analyze these transformations in the teacher-student relationship in times of the so-called digital culture.

KEYwords: Digital culture. Semiformation. Culture industry. Pedagogical link.

\section{LA CULTURA DIGITAL, LA SEMI-FORMACIÓN Y EL NUEVO ESLABÓN PEDAGÓGICO}

RESUMEN: Actualmente los individuos se envician por estímulos audiovisuales, los cuales son propagados por monitores omnipresentes en todas las relaciones sociales. En ascensores y hasta en bares y restaurantes llenos, donde se transmiten las noticias más actuales, se nota la presencia del monitor que se universaliza en las relaciones de trabajo y de tiempo libre, las cuales, no por casualidad, están cada vez más próximas. 
Frente a ese contexto histórico, se hace imprescindible analizar el modo como las nuevas formas de producción y diseminación de las informaciones redireccionan los vectores de la relación profesor-alumno. Siguiendo esta línea de razonamiento, el principal objetivo de este artículo es analizar las transformaciones de la relación profesor-alumno en los tiempos de la llamada "cultura digital".

Palabras Claves: Cultura Digital. Semi-formación. Industria Cultural. Eslabón Pedagógico.

\section{REFERÊNCIAS}

ADORNO, T.W. Studiens in the authoritarian personality. In: ADORNO, T.W. Gesammelte Schriften 9 - Soziologische Schriften II - Erste Hälfte. Frankfurt am Main: Suhrkamp Verlag, 1972.

. A indústria cultural. In: COHN, G. (Coord.). Theodor W. Adorno. São Paulo: Ática, 1994. (Coleção grandes cientistas sociais).

. Teoria da semiformação. In: PUCCI, B.; ZUIN, A. A. S.; LASTÓRIA, L. A. C. B. (Org.). Teoria crítica e inconformismo: novas perspectivas de pesquisa. Trad. Newton Ramos-de-Oliveira. Campinas: Autores Associados, 2010.

ANDERS, G. Die Antiquiertheit des Menschen I. München: C. H. Beck, 2002.

BOURDIEU, P. Contrafogo: táticas para enfrentar a invasão neoliberal. Trad. Lucy Magalhães. Rio de Janeiro: Jorge Zahar, 1998.

FOUCAULT, M. Vigiar e punir: nascimento da prisão. Trad. Raquel Ramalhete. Petrópolis: Editora Vozes, 2001.

HORKHEIMER, M; ADORNO, T. W. Dialética do esclarecimento: fragmentos filosóficos. Trad. Guido Antonio de Almeida. Rio de janeiro: Jorge Zahar, 1986.

HUXLEY, A. Brave new world. London: Vintage, 2007.

KANT, I. Ideia de uma história universal de um ponto de vista cosmopolita. Trad. Rodrigo Naves e Ricardo R. Terra. São Paulo: Brasiliense, 1986.

. Resposta à pergunta: que é esclarecimento. In: KANT, I. Textos seletos. Trad. Floriano de Sousa Fernandes. Petrópolis: Vozes, 2005.

MENCHEN, D. Aluna é suspensa após postar lições no Facebook. In: Folha de São Paulo, Caderno Ribeirão, p. 11, 14. jun.. 2011.

REALE, G.; ANTISERI, D. História da filosofia: do humanismo a Kant. São Paulo: Edições Paulinas, 1990.

ROUSSEAU, J-J. Emílio ou da educação. Trad. Sérgio Milliet. Rio de Janeiro: Bertrand Brasil, 1992.

SCHANK, P.; KRAJCIK, J.; YUNKER, M. Can nanoscience be a catalyst for educational reform? In: ALLHOF, F.; LIN, P.; MOOR, J.;WECKERT, J. (Org.). Nanoethics - the ethical and social implications of nanotechnology. New Jersey: John Wiley \& Sons, 2007. p. 277-290. 
SCHÖNBERGER, V. M. Delete: the virtue of forgetting in the digital age. Princeton: Princeton University Press, 2009.

TÜRCKE, C. Sociedade excitada: filosofia da sensação. Trad. Antônio Zuim, Fábio Durão, Francisco Fontanella e Mario Frungillo.Campinas: Editora da Unicamp, 2010.

ZUIN, A. A. S. Violência e tabu entre professores e alunos: a internet e a reconfiguração do elo pedagógico. São Paulo: Cortez, 2012.

ANTÔNIO A. S. ZuIN é doutor em Educação pela Universidade Estadual de Campinas, com estágio doutoral na Universidade Johann Wolfgang von Goethe, Alemanha e pós-doutorado em Filosofia da Educação pela Universidade de Leipzig, Alemanha; professor-doutor associado da Universidade Federal de São Carlos; editor-associado da revista Educação e Sociedade (CEDES/UNICAMP); membro do conselho editorial da revista Pädagogische Korrespondenz (Frankfurt am Main, Alemanha); bolsista-pesquisador do CNPq desde 2003, assessor da FAPESP desde 2000 e da CAPES desde 2012; professor-visitante do Departamento de Educação da Universidade de York, Inglaterra, por meio do Programa de Intercâmbio com Grupos de Pesquisa do Exterior promovido pela FAPESP (BPE).

E-mail: dazu@ufscar.br 